\title{
James H. Beaty, James R. Kasser (eds.), John M. Flynn, David L. Skaggs, Peter M. Waters (Ass. eds.): Rockwood and Green's fractures in children, 7th edn
}

\author{
Lippincott, Williams \& Wilkins, Philadelphia, December 2009, 00 USD 156,00, \\ pp.: 1096; ill.: 2050, ISBN 13: 978-1-158255-784-7
}

\section{Claude Karger}

Received: 20 December 2010/ Accepted: 21 December 2010/Published online: 5 January 2011

(C) Springer-Verlag 2010

This is the seventh edition of the very well known and always appreciated "Rockwood and Wilkins' Fractures in Children", edited by James H. Beaty from the Campbell Clinic in Memphis and by James R. Kasser from the Children's Hospital of Boston.

For this new edition, all the contributors, both old and new, have made substantial updates to their chapters to ensure that the most current findings are available about new techniques, clinical outcomes, and basic science research. As with every previous edition, the authors have tried to improve not only the information presented but also the way it is presented, to make access and understanding easier. More color illustrations, new graphics, and new formatting have been used in an effort to make this edition more "user-friendly" for the readers.

The textbook is presented in four sections: basic principles, upper extremity, spine, and lower extremity.

In the first section, numerous general topics are developed, such as epidemiology, pain, management of multiply injured children, physeal injuries, pathologic fractures, and child maltreatment.
In the three following sections, all the major locations of upper and lower limb trauma, as well as spinal injuries, are thoroughly described. Each chapter presents the clinical findings, imaging techniques, classification, treatment options, techniques, and complications. At the end of the treatment paragraph, the author outlines what is his preferred choice. Illustrations are abundant and clearly presented, and so are the references.

The purchase of the textbook includes online access to the fully searchable text, image bank, and videos.

Rockwood and Wilkins' Fractures in Children is one of the most outstanding textbooks on pediatric trauma, presented in one volume format. It is an important resource for anyone who manages musculoskeletal injuries in childhood, from the junior resident to the fellow and the senior orthopedic surgeon. It will also be of major interest for pediatricians, radiologists, and physical therapists.

Conflict of interest No funds were received in support of this study.

C. Karger $(\bowtie)$

Strasbourg, France

e-mail: karger.claude@wanadoo.fr 